\title{
RELIGIOY MAGIA EN ENEIDA: ANÁLISIS DE LA TRANSFORMACIÓN DE LA REINA DIDO
}

\author{
Religio and Magic in Aeneid: Analysis of Queen Dido's Transformation
}

\author{
Guillermina Bogdan* \\ Universidad Nacional de La Plata \\ guillerminabogdan@hotmail.com
}

Palabras clave

Eneida;

Dido;

religio;

magia

Keywords

Aeneid;

Dido;

religio;

magic

\section{Resumen}

El estudio se centra en las prácticas rituales de la reina de Cartago en Eneida, que presentan tanto elementos de la religio romana como de la magia. Dicha dualidad muestra no solo la devoción de la reina ante las divinidades, sino también la aparición de elementos extranjeros propios de la magia representados en un rito africano trasmitido por una sacerdotisa de raza masila combinado con un supuesto sacrificio a Júpiter Estigio. De este modo, nos interesa analizar la transformación que sufre el personaje a partir de la incitación divina y cómo dicha metamorfosis se plasma en sus prácticas que evidencian la oposición incipiente, nacida a finales de la República y profundizada en el período imperial, entre la magia y la práctica religiosa normativa.

\begin{abstract}
The study focuses on the ritual practices of the Queen of Carthage in Aeneid, which present both elements of Roman religio and magic. This duality shows not only the queen's devotion to the divinities, but also the appearance of foreign elements typical of magic represented in an African rite transmitted by a Masila priestess combined with an alleged sacrifice to Jupiter Stygian. In this way, we are interested in analyzing the transformation that the character undergoes from divine incitement and how this metamorphosis is reflected in her practices that evidence the incipient opposition, born at the end of the Republic and deepened in the Imperial period, between magic and normative religious practice.
\end{abstract}




\section{Religio y magia en Eneida: Análisis de la transformación de la reina Dido ${ }^{1}$}

La crítica virgiliana se ha ocupado de analizar el personaje de Dido desde diversas e interesantes perspectivas: la representación particular hecha por Virgilio, ${ }^{2}$ su configuración híbrida en cuanto a los estudios de género en la épica clásica, ${ }^{3}$ su compleja formación como personaje, ${ }^{4}$ su comparación mítica ${ }^{5}$ o histórica, ${ }^{6}$ entre muchas otras. Teniendo en cuenta, por un lado, algunas de dichas perspectivas y, por otro, estudios tanto de la función ritual como de su perspectiva histórica, el trabajo partirá del análisis filológico literario de los ritos ejecutados por la reina para evidenciar la transformación que las prácticas van sufriendo a medida que Dido es envuelta en la pasión amorosa. El proceso de enamoramiento, profundizado por las estrategias divinas de Venus y luego de Juno, desarrollará en la reina diferentes estados de ánimo que conversarán con su comportamiento religioso: desde rituales propios de la religio romana hasta prácticas mágicas orientales. Creemos que dicha conversión está intencionalmente propuesta por el poeta para explicitar la oposición entre la magia y la práctica religiosa normativa. ${ }^{7}$

Si tenemos en cuenta estudios sobre el desenvolvimiento emocional de la reina, ${ }^{8}$ podemos observar la transformación de sus sentimientos a lo largo de los libros I y IV. A continuación, analizamos dichos episodios y, como dijimos anteriormente, destacamos la intervención divina, no para reducir el estudio a un enfrentamiento entre dioses, sino porque estas relaciones no dejan de ser parte de una comunicación entre la esfera humana y la divina.

\section{Lapietas de Dido}

Recordemos que en el libro I, Eneas y su flota desembarcan en Cartago. Allí una embajada mandada por el héroe se presenta ante la reina quien le da la bienvenida a la ciudad. Ya desde el primer encuentro, Venus, madre del líder troyano lo protege con una nube (I. 414) que al desaparecer y al presentarse ante la reina: "Eneas se asemeja a un dios" (I. 588) gracias al efluvio provocado (I. 589590). Venus, no quedándose tranquila con esta pequeña intervención y temiendo por el rechazo de la reina hacia su hijo y sus compañeros, lleva a cabo el siguiente plan: Aprovecha la ausencia del hijo de Eneas, Ascanio, y lo reemplaza por la de su hijo Cupido, para que mientras el pequeño dios acompañe

1. Agradezco a los evaluadores anónimos por las correcciones y por los consejos dados que ayudaron a mejorar el estudio.

2. Ver: La Penna, 1985, p. 48-63; Heinze, 1996, p. 151-180, entre otros.

3. Ver: Nugent, 1999 , p. 251-270.

4. Horsfall, 1995, p. 123-134; Dyson, 1996, p. 203-221.

5. Ver: Schiesaro, 2008, p. 65 y ss.

6. Ver: Gharbi, 1990, p. 22; Syed, 2005, p. 180-191; Martínez Astorino, 2020, p. 275-292; Santos Pinheiro, 2010 , p. $74-75$.

7. Ver: Bremmer, 1999, p. 10; Marco Simón, 2001, p.106.

8. Schiesaro (2008, p. 60-245) analiza a partir del tratamiento influyente de Heinze cómo los críticos modernos describen la imagen de Dido como una heroína enamorada y desamparada cuyos estallidos de furia son evanescentes y justificados. Sin embargo, el autor propone una lectura que destaca las complejidades intertextuales del personaje de Dido y las relaciona con lo que él llama "el impulso inconsciente". 
a la reina, ella arda de pasión por el héroe troyano y así no cambie de parecer en cuanto a la buena predisposición de asilo. Dicha estrategia sucede en el marco de una libatio, ritual característico de la religio:

Postquam ${ }^{9}$ prima quies epulis, mensaeque remotae, crateras magnos statuunt et vina coronant.

Fit strepitus tectis, vocemque per ampla volutant atria; dependent lychni laquearibus aureis incensi, et noctem flammis funalia vincunt. Hic regina gravem gemmis auroque poposcit implevitque mero pateram, quam Belus et omnes a Belo soliti; tum facta silentia tectis:

'Iuppiter, hospitibus nam te dare iura loquuntur, hunc laetum Tyriisque diem Troiaque profectis esse velis, nostrosque huius meminisse minores. Adsit laetitiae Bacchus dator, et bona Iuno; et vos, $\mathrm{O}$, coetum, Tyrii, celebrate faventes.' Dixit, et in mensam laticum libavit honorem, primaque, libato, summo tenus attigit ore, tum Bitiae dedit increpitans; ille impiger hausit spumantem pateram, et pleno se proluit auro post alii proceres. Cithara crinitus Iopas personat aurata, docuit quem maximus Atlas.

Después que ha habido un primer descanso en los banquetes y han sido quitadas las mesas, ponen grandes cráteras y coronan las copas. El bullicio llena los techos, $\mathrm{y}$ hacen rodar la voz por los amplios atrios; las lámparas encendidas penden de los dorados artesones, y las antorchas vencen a la noche con sus llamas. Allí pidió la reina una pesada copa de oro y piedras preciosas, que solía usar Belo y sus descendientes, y la llenó de vino. Entonces, habiendo sido hecho el silencio bajo el palacio: "Júpiter, pues dicen que está a tu cargo el derecho de hospitalidad, ojalá permitas que sea éste un día alegre para los tirios y cuantos salieron de Troya, y que de él se acuerden nuestros descendientes! Que nos asista Baco, dador de la alegría, y la buena Juno; y vosotros joh tirios! Celebrad favorables esta reunión”. Dijo y derramó en la mesa la ofrenda de los líquidos, y, derramada, tocó primera la copa solo con el borde de la boca; luego se la dio a Bicias incitándolo a beber; él, no perezoso, apuró la espumante copa, y se humedeció la boca hasta llegar al oro macizo; después, los otros distinguidos. Canta con la dorada cítara el crinado Iopas, al cual enseñó el muy gran Atlante. ${ }^{10}$

Se describen, entonces, los pasos de la libación: Primero, se ve la acción de rodear las copas con guirnaldas de flores, especialmente la copa de oro usada por Belo, rey tirio, padre de Dido. La plegaria incluida en la libación es dedicada a Júpiter, quien según ésta dictó las leyes de hospitalidad (v. 730), ${ }^{11}$

9. Para el texto latino se sigue la edición de Mynors (1969). Las traducciones son nuestras.

10. Dicho episodio es estudiado por Dyson (1996, p. 203-221) en relación con el lujo destacado y en oposición a las relaciones posteriores del héroe (Latino-Evandro).

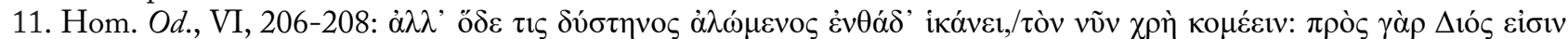

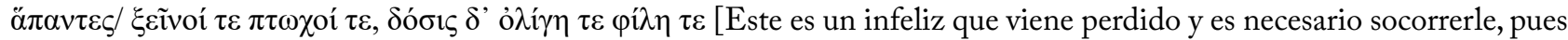
todos los extranjeros y pobres son de Zeus]. 
por eso se establece la unión pacífica entre tirios y troyanos. La copa ofrecida es tomada por Dido, quien solo apoya los labios y la pasa al resto de los integrantes. La práctica es propuesta por la tiria para sellar la hospitalidad del pueblo cartaginés hacia el troyano, y sus componentes representan el símbolo de esta unión. Aunque los dioses con los que se quiere instaurar la pax deorum no son cartagineses (Júpiter y Baco), el poeta recuerda que la copa fue usada por el padre de Dido, haciendo de la libatio un ritual con elementos de ambas etnias. Otro aspecto importante es que la función argumental del episodio es describir el momento en que la reina, luego de la libación, continúa bebiendo en compañía de Cupido y es por eso que el poeta afirma: infelix Dido, longumque bibebat amorem (v. 749); razón por la cual la práctica funciona como antesala de la futura unión. ${ }^{12}$ Por un lado, el rito, según Maisonneuve (2005, p. 11), desempeña un papel indudablemente irremplazable en el mantenimiento y el refuerzo del vínculo social y, simultáneamente, en la consagración de las diferencias de estatuto compensadas por una articulación de los roles de ambos pueblos. Por otro lado, se observa cómo Dido promueve la paz con los troyanos por medio de la invocación a Júpiter, el dios rector y quien penará a continuación el accionar de la reina y del héroe, pero con quien en este primer estadio establece la pax deorum a través de la demostración de su pietas.

\section{Primera "desviación"}

Una vez concluido el ritual, Dido, incitada por el propio Cupido, comienza a caer en el ardor amoroso y le pide a Eneas que cuente los relatos de la huida de Troya. Los libros II y III estarán en boca del héroe quien narrará sus aventuras. Ya en el libro IV encontramos a una Dido profundamente presa del amor por Eneas; y su primera imagen será la de la desesperación de la reina y la confesión frente a su hermana. Si bien en el libro I, el poeta había manifestado la atracción de la reina hacia el héroe, es en este episodio en donde dicha atracción se convierte en un conflicto, y las emociones de Dido comienzan a exteriorizarse: La reina tiene dudas sobre su posición y le pide consejos a Ana sobre lo que debe hacer. Le confiesa que prefiere que el padre omnipotente la arroje a las sombras con su rayo antes que violar la honestidad (vv. 24-25). Su hermana argumentará a favor de la unión con Eneas desde varias perspectivas estudiadas usualmente por la crítica: ${ }^{13}$ la ausencia de descendencia, la seguridad de tener un hombre al lado, el poder que podrían tener los dos pueblos unidos, etc. Dido pide estos argumentos una vez que está presa del amor generado por Cupido: la culpa busca excusas para romper sus votos de univira, y Ana se las da.

Luego de los consejos, vemos el inicio de las mutaciones en el ánimo y, en consecuencia, en su actividad ritual:

12. Según Panoussi (2009, p. 98), el sacrificio que Dido realiza en honor de Baco es todavía otro ejemplo de la posibilidad de múltiples lecturas del episodio. Por ejemplo, lo compara con el banquete de una boda en la que están los invitados de los novios, debido a la descripción hecha por el poeta: laeta limina, 707; laetum ... diem, 732; laetitia, 734. Por último, cuando Venus provoca el sueño de Ascanio de manera que Cupido puede hacerse pasar por él, ella lo envuelve con flores de mejorana (amaracus, 693). La planta es mencionada en Catulo, 61, vv.6-7, específicamente en la descripción del dios del matrimonio, Himeneo: cinge tempora floribus /suaue olentis amaraci (corona tus sienes con las flores de la mejorana que huele). Así la autora relaciona el banquete con el festejo de una futura boda.

13. Ver: Heinze, 1996, p. 157-161; Dyson, 1996, p. 214; Schiesaro, 2008, p. 91 y ss., entre otros. 
tu modo posce deos veniam, sacrisque litatis indulge hospitio causasque innecte morandi, dum pelago desaevit hiems et aquosus Orion, quassataeque rates, dum non tractabile caelum. His dictis impenso animum flammavit amore spemque dedit dubiae menti solvitque pudorem. principio delubra adeunt pacemque per aras exquirunt; mactant lectas de more bidentis legiferae Cereri Phoeboque patrique Lyaeo, Iunoni ante omnis, cui vincla iugalia curae. ipsa tenens dextra pateram pulcherrima Dido candentis vaccae media inter cornua fundit, aut ante ora deum pinguis spatiatur ad aras, instauratque diem donis, pecudumque reclusis pectoribus inhians spirantia consulit exta. heu, vatum ignarae mentes! quid vota furentem, quid delubra iuvant?

"Pide tú ahora su venia a los dioses, y, ofrecidos los sacrificios, date a la hospitalidad, y busca causas para demorarlos, mientras el invierno y el lluvioso Orión descargan su ira en el piélago, y sus naves están rotas, y el cielo es tempestuoso". Con estas palabras inflamó su pecho encendido por el amor, y dio esperanza a su dudosa mente y quebrantó su pudor. Van primero a los templos, y tratan de encontrar la paz en los altares, sacrifican, según el rito, ovejas elegidas según las leyes, a Ceres, y a Febo, y al padre Lieo, a Juno ante todos, para la cual son de cuidado los vínculos conyugales. La misma hermosísima Dido, teniendo en la diestra la pátera, la derrama en el medio de los cuernos de una blanca vaca, y se pasea junto a los grasientos altares ante la presencia de los dioses, renueva cada día con sus dones, y ansiosa consulta en los abiertos pechos de los animales las palpitantes entrañas. ¡Ay! ¡Ignorantes mentes de los vates! ¿en qué ayudan los votos, en qué los templos a una apasionada?

Ana le recomienda hacer los debidos sacrificios. En consecuencia, se dirigen al templo, realizan una plegaria por la paz, sacrifican ovejas selectas para Ceres, llamada legiferae por ser la que estableció las leyes agrícolas, a Febo, a Baco con su sobrenombre Lieo (el relajador, el que desata o libera) ${ }^{14}$ y a Juno como patrona del matrimonio. Según Bailey (1935, p. 56), el lugar de Juno es claro, en cuanto a Febo,

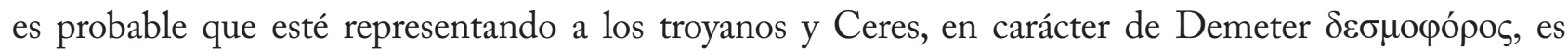
nombrada para asegurarse el establecimiento de una nueva colonia. ${ }^{15}$ Luego se describe la libatio ${ }^{16}$ en la

14. Ver: Pérez y Barro, 2004, p. 116.

15. "Ceres, Apollo, and Bacchus are mentioned in the Pervigilium Veneris as deities of marriage. And Virgil himself has illustrated the passage, for on the previous night Dido had made prayer to Iuppiter, the protector of strangers, and asked for the presence of Bacchus giver and kindly Iuno (731-734). Ceres and Lyaeus then may be here as deities of hospitality and feasting. But probably several motives may have worked in Virgil's mind towards his choice" (Henry en Bailey, 1935, p. 56). 16. Según Fowler (2008, p. 169-179), antes del sacrificio de la víctima se rociaba sobre ella partes de la torta sagrada (immolatio) y libaciones de vino. Luego, se examinaban los órganos internos para asegurarse de que no existía ningún defecto físico o crecimiento anormal, pues era necesario que el animal sea purus tanto por dentro como por fuera; éste era el único objeto del examen, hasta que el arte etrusco de extipicina hizo su camino en Roma. Los exta, es decir, los órganos internos de la vida, se separaban del resto de la carne, y eran preparados en los vasos sagrados, antes de ser puestos sobre el altar (porrectio), junto con algunas rebanadas de carne llamadas magmenta. 
que se derrama el vino en medio de los cuernos de la vaca blanca como don a los dioses. Una vez iniciado este pacto en el que se ofrecen tales prácticas, se describe cómo la reina no pudiendo esperar (inhians v. 64), realiza ella misma la observación de las entrañas. Aunque no se describa el resultado de la inspección de las vísceras, se emplea como técnica reconocida para demostrar la ansiedad de la reina por lo que el futuro le depare en su ardor amoroso. La actitud descripta junto a su estado de furentem pareciera oponerse a su anterior comportamiento piadoso y a cualquier actitud propia de la pietas en cuanto a la disposición de ánimo y mente apta para ejecutar un ritual (Maisonneuve, 2005, p. 17). Por último, ella misma destaca este antagonismo y se pregunta quid vota furentem, quid delubra iuvant, cuestionando la utilidad de los ritos que no serán suficientes, y la dificultad de establecer la pax deorum.

\section{Respuesta de los dioses}

A continuación, el poeta describe el encuentro entre Venus y Juno (90-117). Esta da cuenta de haber descubierto la estrategia de la madre del héroe y propone unirse al objetivo para que ambos pueblos formen su destino allí, oponiéndose claramente a los hados pronunciados por Júpiter. Ahora la intervención de Juno pondrá más peso en la pasión de la reina: la diosa hará que Dido y Eneas se encuentren amorosamente en una cueva luego de desatar una tormenta durante una cacería. En el simulacro de himeneo, ${ }^{17}$ como así lo refiere el poeta ("Lo llama matrimonio para velar su culpa", IV, 170), Dido cae completamente presa de pasión por el héroe siendo éste su única ocupación y preocupación. Como recordamos, Jarbas, antiguo pretendiente, invoca a Júpiter para pedirle una explicación sobre el accionar de la reina. El dios sorprendido no por el comportamiento de Dido, sino por la desobediencia del héroe ante el mandato fundacional, manda a Mercurio a despertarlo y exigirle que abandone la playa. ${ }^{18}$

En los versos 450-455, Dido, luego de la decisión de partida de Eneas, comienza a ver su propio fin:

Tum vero infelix fatis exterrita Dido

mortem orat; taedet caeli convexa tueri.

quo magis inceptum peragat lucemque relinquat,

vidit, turicremis cum dona imponeret aris,

(horrendum dictu) latices nigrescere sacros

fusaque in obscenum se vertere vina cruorem;

hoc visum nulli, non ipsi effata sorori.

(IV, 450-455)

Pero entonces la infeliz Dido, aterrada por los hados, suplica la muerte; le da tedio mirar la bóveda del cielo. Para animarse a llevar a cabo su plan y abandonar la luz, vio (cosa horrenda de decir), al dejar sus ofrendas sobre los altares donde se quema el incienso, ennegrecerse los sagrados líquidos y los vinos derramados convertirse en una sangre inmunda. A nadie, ni a su misma hermana, ha contado la visión.

17. Para las discusiones y bibliografía sobre este pasaje ver Horsfall (1995, p. 127).

18. Cuando el dios se presenta ante el héroe, este no solo le da el mensaje del dios de dioses sino que Eneas "se queda sin sentidos" (v. 279) lo que impedirá que "escuche" las quejas tanto de Ana como de Dido. Nuevamente la divinidad altera el comportamiento humano. Para el estudio de Mercurio en la obra ver Fratantuono, 2015, p. 295-310. 
Se observa en este caso una contestación divina hacia la nueva ofrenda y la libatio de la reina que prefigura su futuro accionar y el desenlace. Los dioses a través de la conversión de la ofrenda líquida en sangre responden negativamente al nuevo pedido, en consecuencia, se profundizan los rasgos impropios de la actitud para la ejecución de un ritual: en aquella primera instancia se la describió como inbians, aquí ya exterrita por la respuesta. Nuevamente es ella la que interpreta la respuesta y, en este caso, no se lo menciona ni a su hermana, para poder así intentar manipular el porvenir a través ya no de prácticas rituales normativas sino mágicas.

\section{De la religio a la magia}

A partir del verso 478, Dido le dice a su hermana que hará un rito africano trasmitido por una sacerdotisa de raza masila a quien la reina habría acudido contra su voluntad, y le da ciertas indicaciones:

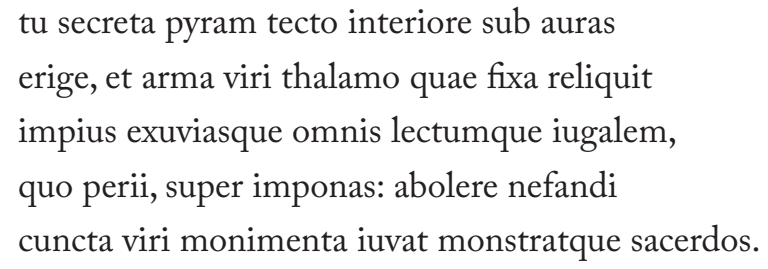

Tú levanta secretamente una pira en el interior del palacio, al aire, y pon encima las armas de ese varón, las que dejó el impío colgadas en el tálamo, y todas sus prendas, y el lecho conyugal en que perecí: quiero destruir todos los recuerdos de ese varón infame, y lo indica la sacerdotisa.

Este pasaje es discutido por la crítica ${ }^{19}$ en cuanto a si es un ritual de magia para olvidar a Eneas o para atraerlo. A este respecto, Tupet (1971, p. 229-258) concluye que la muerte de la reina es el sacrificio que completa tanto el ritual de olvido como el de destrucción ya que junto a ella se quema la imagen de Eneas. Por su parte, Silva (2020, p. 1-14) hace un interesante estudio que defiende la hipótesis de que al quemar sus pertenencias, Dido intenta olvidar a Eneas y no destruirlo; para ello, analiza este episodio a la luz de las fuentes no literarias y de la tradición poética sobre la magia del amor y el borrado de la memoria. Concluye afirmando que uno de los principales objetivos de los hechizos relacionados con la memoria y el amor era inquietar a las víctimas, no destruirlas. Asimismo señala que la reina también podría estar bajo la influencia de esta fuerza mágica que la obligó a olvidar a Siqueo y enamorarse de Eneas, sin tener en cuenta sus deberes.

Más adelante tendrá lugar el accionar mágico de la reina:

At regina, pyra penetrali in sede sub auras erecta ingenti taedis atque ilice secta, intenditque locum sertis et fronde coronat

19. Ver: Tupet, 1971, p. 229-258; Martínez 2003, p. 241-245; Pinheiro 2010, p. 46; Seider 2013, p. 119-120; Silva, 2020, p. $1-14$. 
funerea; super exuvias ensemque relictum effigiemque toro locat haud ignara futuri. stant arae circum et crinis effusa sacerdos ter centum tonat ore deos, Erebumque Chaosque tergeminamque Hecaten, tria virginis ora Dianae. sparserat et latices simulatos fontis Averni, falcibus et messae ad lunam quaeruntur aenis pubentes herbae nigri cum lacte veneni; quaeritur et nascentis equi de fronte revulsus et matri praereptus amor.

ipsa mola manibusque piis altaria iuxta unum exuta pedem vinclis, in veste recincta, testatur moritura deos et conscia fati sidera; tum, si quod non aequo foedere amantis curae numen habet iustumque memorque, precatur.

(IV, 504-521)

Y la reina, erigida bajo las auras una gran pira de teas y encina cortada en el fondo del palacio, adorna aquel lugar con guirnaldas y con una corona de fúnebre fronda; coloca sobre el lecho ${ }^{20}$ los despojos, y la espada dejada, y una imagen, no ignorante de lo que ha de suceder. Se alzan los altares alrededor y la sacerdotisa, teniendo sueltos los cabellos, llama con voz tonante tres veces cien dioses con su boca, tanto al Erebo como al Caos, y a la triforme Hécate y a las tres caras de la virgen Diana. Y había esparcido aguas que simulaban las de la fuente del Averno, y busca hierbas tiernas, con leche de negro veneno, segadas a la luz de la luna con hoces de bronce y se busca el amor, arrancado de la frente del caballo naciente arrebatado a su madre. Ella misma, con la mola y con piadosas manos, junto a los altares, habiendo despojado un pie de sus ligaduras, desceñida en su vestidura, pone por testigos, habiendo de morir, a los dioses y a los astros, conocedores de su hado; entonces, si algún numen justo y memorioso tiene para cuidado a los amantes con una alianza no igual, le suplica.

Faraone sostiene que este ritual puede reconstruirse de la siguiente manera: una figura masculina de cera es vestida y atada con cintas multicolores junto con una figura femenina de barro; ambas son puestas en el fuego que ablanda y destruye una de ellas, mientras que cocina y endurece la otra: La de cera tiene como objetivo ablandar al cruel y la de barro, endurecer a la mujer para darle valor en sus acciones futuras. ${ }^{21} \mathrm{La}$ imagen de la sacerdotisa con el pelo suelto representa la idea de no "trabar" el ritual con ningún nudo. Luego nombra a los trescientos dioses, Erebo y al Caos y a la triple Hécate, los tres aspectos de la virgen Diana. La apelación a los dioses del inframundo en un rito mágico es natural, ${ }^{22}$ no siendo propio en un rito religioso. Más adelante agrega, en la acción de ofrecer la comida

20. Siguiendo a Clausen (2002, p. 97-98): "These few lines are dense with meaning. Of the twenty occurrences of thalamus in the Aeneid all but one or two refer to marriage or the marriage chamber. "Pius Aeneas" is denounced as "impius", and the adjective uses only twice elsewhere in the Aeneid of persons, of the murderer Pygmalion (1.349) and the sacrilegious Diomedes (2.163). Lectus is a common word, too common or low in general to be used in epic, but Virgil wishes to remind his readers of the legal term for marriage bed, lectus genialis, and does so by enhancing lectus with the adjective borrowed from Catullus (64.302 "Taedas...iugalis", referring to the marriage of Peleus and Thetis, another unhappy marriage, iugalis first occurs in Catullus. This device- enhancing a common word with a poetic adjective- was recognized in antiquity). In an erotic sense, pereo is found mostly in comedy and elegy; here, however, the sense or implication of "perii" is not simply erotic: Dido "died" on her marriage bed, and on that same bed she will now died".

21. Ver: Faraone, 1989, p. 299-300.

22. Ver: Bailey, 1935, p. 199. 
sagrada, elementos de un rito religioso romano, junto con las manos piadosas (piis manibus) al lado del altar, con un pie desatado de las ligaduras y teniendo desceñidas las vestiduras, les hace una plegaria a los dioses antes de su muerte. Si bien la religio se mezcla con la magia aquí en la apelación a los dioses, el contenido principal de la práctica es la magia primitiva. Con respecto a la presencia de los dioses, Bailey (1935, p. 200) afirma:

Here is Artemis in her character of the chtonic Hecate, yet with remembrance of her conexion with the upper world and, as the moon, with the sky, Erebus the personified lower world of mythology, and Chaos, its cosmological counterpart. There is no record of a sacrifice to Hecate, but she is once invoked for aid by Dido. Hecate is combined with the Greek Erebos and Chaos, and that Hecate is definitely thought of as the lower-world counterpart of the Greek Artemis.

Asimismo, esta combinación de elementos de ambas esferas se ve al nombrar a la hechicera como una sacerdotisa: ${ }^{23}$ podemos pensar como Stroppini (2003, p. 106-107) que se debe a que en un primer período, las funciones de sacerdote y hechicero no estaban aún diferenciadas la una de la otra, o podemos creer, al estudiar la evolución de las prácticas de Dido, que este híbrido de elementos esté intencionalmente expresado por el poeta para destacar la transformación de su acción religiosa. Entre los versos 504 y 516 se ven los elementos que representan y caracterizan el rito mágico y que son comparables con los de la Bucólica VIII de Virgilio, como apunta Stroppini (2003, p. 106). El ritual aquí realmente no es un acto de magia para atraer al amado, porque aunque los elementos mágicos estén presentes, la actitud de la hechicera y sobre todo su intención deben siempre estar en concordancia con el rito que se practica, en cambio, Dido es presa del furor y su accionar no es apropiado para efectivizar la práctica si así fuese su objetivo.

Luego, una vez que la reina ve a la flota de Eneas dejar la costa (v. 586), se desata aún más su ira e invoca inicialmente a Júpiter (v. 590) y luego, el poeta aclara en boca de la reina que la totalidad de la práctica se excusa en ser un rito a Júpiter Estigio (v. 638) ${ }^{24}$ Comienza esta nueva parte con una plegaria al Sol, a Juno, a Hécate y a las Furias. El primero es invocado dos veces en la obra, una por Eneas (XII, VV.175-182), en la que es tomado como una deidad cosmológica de la tradición romana, y esta vez, por Dido:

\footnotetext{
"Sol, qui terrarum flammis opera omnia lustras, tuque harum interpres curarum et conscia Iuno, nocturnisque Hecate triviis ululata per urbes et Dirae ultrices et di morientis Elissae, accipite haec, meritumque malis advertite numen et nostras audite preces. si tangere portus infandum caput ac terris adnare necesse est, et sic fata Iovis poscunt, hic terminus haeret, at bello audacis populi vexatus et armis, finibus extorris, complexu avulsus Iuli auxilium imploret videatque indigna suorum funera; nec, cum se sub leges pacis iniquae
}

23. Para el estudio de la sacerdotisa ver Florio, 1982, p. 38-39; La Fico Guzzo, 2005, p.123.

24. Ver: Bailey, 1935, p. 199; Hejduk, 2009, p. 315. 
tradiderit, regno aut optata luce fruatur, sed cadat ante diem mediaque inhumatus harena.

haec precor, hanc vocem extremam cum sanguine fundo. tum vos, o Tyrii, stirpem et genus omne futurum exercete odiis, cinerique haec mittite nostro munera. nullus amor populis nec foedera sunto. exoriare aliquis nostris ex ossibus ultor qui face Dardanios ferroque sequare colonos, nunc, olim, quocumque dabunt se tempore vires. litora litoribus contraria, fluctibus undas imprecor, arma armis: pugnent ipsique nepotesque". Haec ait, et partis animum versabat in omnis, invisam quaerens quam primum abrumpere lucem. tum breviter Barcen nutricem adfata Sychaei, namque suam patria antiqua cinis ater habebat: "Annam, cara mihi nutrix, huc siste sororem: dic corpus properet fluviali spargere lympha, et pecudes secum et monstrata piacula ducat. sic veniat, tuque ipsa pia tege tempora vitta. sacra Iovi Stygio, quae rite incepta paravi, perficere est animus finemque imponere curis Dardaniique rogum capitis permittere flammae".

(IV, 607-640)

“ $\mathrm{Oh}$, Sol, que alumbras con tus rayos todas las obras de la tierra, y tú, Juno intérprete y sabedora de mis cuitas, y Hécate, ululada por las ciudades en las encrucijadas nocturnas, y vengadoras Furias, y dioses de la moribunda Elisa! Escuchad estas cosas y caed sobre los malvados con justo numen y oíd nuestros ruegos. Si es necesario que ese nefando cuerpo arribe a aquellos puertos y navegue hasta tierra, y así lo exigen los hados de Júpiter, si está determinado este final, que, al menos, perseguido por la guerra y las armas de un pueblo audaz, desterrado de sus territorios, arrancado del abrazo de Julo, implore auxilio, y vea indignas muertes de los suyos; y que, cuando se hubiere entregado bajo las condiciones de una paz injusta, no disfrute de su reino ni de la deseada luz; sino que muera antes de tiempo, y caiga insepulto en medio de la arena. Estas cosas suplico, esta última voz doy con mi sangre. Después, vosotros ¡Oh tirios! Perseguid con vuestros odios su estirpe y todo su futuro linaje, y enviad esos presentes a nuestra ceniza; no haya ningún amor ni alianza entre los dos pueblos. Que salga de nuestros huesos algún vengador, que persiga a hierro y fuego a los colonos dardanios, ahora, en lo sucesivo, en cualquier tiempo en que se encuentren sus fuerzas. Pido que estos litorales sean contrarios a sus litorales, estas ondas a sus olas, estas armas a sus armas; que peleen tanto ellos mismos como sus nietos". Estas cosas dice, y dirigía su ánimo a todas partes, queriendo cortar cuanto antes la luz aborrecida. Entonces, habló brevemente a Barce, nodriza de Siqueo (porque la negra ceniza tenía a la suya en la antigua patria): "Haz de traer aquí, nodriza para mí querida, a mi hermana Ana; dile que traiga consigo los animales y los objetos indicados para las expiaciones; que venga así, y tú misma cubre sus sienes con la piadosa venda. Es mi ánimo acabar los sacrificios a Júpiter Estigio, los cuales he preparado según el rito, y poner fin a mis cuidados, y entregar a la llama la pira del dardanio".

La reina hace una plegaria que evidencia la unión de elementos complejos: invoca al Sol, que ilumina el mundo, a Juno, que conoce el cuidado del amor y el matrimonio, a la fuerte Hécate, a las vengadoras Furias, y “los dioses de la moribunda Elisa”. Más allá de los elementos propios de la plegaria, 
se pide una acción negativa, ${ }^{25}$ por lo que el pedido estaría fuera de la esfera de la religio. Dentro de lo concerniente a la magia, el nombre de Eneas no es pronunciado y es por ello que Silva (2020, p. 1-14) plantea que no se trata de un deseo de destrucción sino de olvido. Según Heinze (1996, p. 167), Virgilio reemplazó el rito funerario destinado por uno mágico, y Tupet, por su parte, señala que el sacrificio de Dido forma parte del ritual mágico y es una inmolación para el cumplimiento del pedido (1971, p. 229258). El último rito con sus características propias e híbridas es, según palabras de la reina, dedicado a Júpiter Estigio, ritual griego, según Bailey (1996, p. 284), pero con los elementos propios de la religio romana. Ofrecido, entonces, al mismo dios que la reina le celebra honores desde el comienzo (I, 731), quien prefiere que la arroje a las sombras antes de quebrantar la honestidad (IV, 24-25) y quien se lleva a Eneas a cumplir su destino, pero en este caso, Estigio, invocando a los poderes del submundo. Destacamos entonces la transformación de la relación piadosa entre la reina y el padre de los dioses.

Marco Simón (2001, p. 106) siguiendo a Tambiah (1990, p. 7) estudia las diferencias entre las dos esferas estudiadas y sostiene que la magia aparece como una acción ritual distintiva, que se cree automáticamente efectiva y que trata con fuerzas y objetos que están fuera del alcance de los dioses o que se cree independiente de ellos y que se opone a la práctica religiosa normativa (Bremmer, 1999, p. 10). Por lo que la desesperación de Dido, su alteración emocional a causa de las consecuencias del hechizo inicial de Venus, la llevan a no aceptar el destino pronunciado por Júpiter y esta no aceptación la vincula con el terreno mágico, espacio caracterizado por la concepción de desviación. Marco Simón (2001, p. 110) afirma que Plinio el Viejo fue el primero que contempló la magia como un sistema amenazador del mos maiorum y, en cuanto tal, definidor de una alteridad que él relacionaba en última instancia con Persia, es decir, con el Imperio parto, adversario universal de las pretensiones igualmente universales de Roma. En este caso, la amenaza no vendrá de Persia sino de Cartago, de la mano de una sacerdotisa-hechicera africana pero luego encubierta en un sacrificio al mismo Júpiter, no solo para que funcione míticamente como el preámbulo del conflicto con dicho pueblo, sino también para esquematizar y, por qué no estigmatizar, un tipo de metamorfosis producida por la alteración del ánimo de un ser en particular y plasmado en una práctica no aceptada por la Roma augustea.

\section{Conclusión}

Como observamos a lo largo del estudio, existe un paralelismo entre los cambios emocionales de la reina y las prácticas realizadas: Inicialmente Dido acepta la llegada de Eneas y esta actitud es representada por el rito correspondiente a la religio tradicional en la que se les da hospitalidad a los troyanos. Luego de la intervención divina, la reina le confiesa su nuevo sentir a su hermana y ambas consultan a los dioses. Resaltamos en este sacrificio su ansiedad como sentimiento no adecuado para la ejecución de una práctica religiosa. A partir de la nueva participación tanto de Juno como de Júpiter y la decisión de Eneas de dejar Cartago, las emociones de Dido sufren nuevos cambios, y el rito que ejecuta tiene una respuesta negativa que ella calla para dar paso a otro tipo de procedimiento vinculado con la magia. Según las prácticas rituales analizadas pareciera que a menor aceptación del destino

25. Para el análisis de la maldición de Dido ver Clausen, 2002, p. 99. 
mayor alteración emocional y, en consecuencia, mayor relación con lo alterno, en este caso, con un ritual con más elementos mágicos que del ámbito de la religio.

Dido representa entonces los dos extremos de la conexión del mundo divino y humano: la religio demostrada por su forma pragmática, su pietas; y una vez alterados su sentidos, la ansiedad que convierte esa aceptación en manipulación y a ella no solo en una víctima de los dioses, sino en una practicante de un ritual supuestamente ofrecido al pronunciador del fatum, pero con claros elementos mágicos y con la intención trastocada que convierte a una plegaria en una maldición, y a la practicante en víctima de sacrificio.

\section{Referencias bibliográficas}

Bailey, C. (1935). Religion in Virgil. Oxford, Clarendon University Press.

Bremmer, J. N. (1999). The birth of the term Magic. ZPE, 126, 1-12.

Clausen, W. (2002). Virgil's Aeneid: Decorum, Allusion and Ideology. München, Leipzig.

Dyson, J. T. (1996). Dido the Epicurean. Classical Antiquity, 15 (2), 203-221.

Faraone, C. A. (1989). Clay Hardens and Wax Melts: Magical Role-Reversal in Vergil's Eighth Eclogue. $C P h, 84,294-300$.

Florio, R.(1982).Dido y Eneas, polos de la concepción histórico mítica de Virgilio. Bahía Blanca, Universidad Nacional del Sur.

Fowler, W. (2008). The Religious Experience of the Roman People. Edinburgh, Echo Library.

Fratantuono, L. (2015). Lethaeum ad fluvium: Mercury in the Aeneid. Pallas, 99, 295-310.

Gharbi, B. (1990). Infelix Amor; Thématique de Didon dans le chant IV de L'Éneide. En Martin, R. (ed.), Énée et Didon: naissance, fonctionnement et survie d'un mythe (pp. 11-22). Paris, CNRS.

Heinze, R. (1996). La tecnica epica di Virgilio. Bologna, Societá editrice di Mulino.

Hejduk, J. (2009). Jupiter's Aeneid: Fama and Imperium. Classical Antiquity, 28, 279-327.

Horsfall, N. (1995). A Companion to the Study of Virgil. Leiden-New York-Köln, Brill.

La Fico Guzzo, M. L. (2005). Espacios simbólicos en la Eneida de Virgilio. Bahía Blanca, Ediuns.

La Penna, A. (1985). Didone. Encilopedia Virgiliana, 2, 48-63.

Maisonneuve, J. (2005). Las conductas rituales. Buenos Aires, Nueva Visión.

Marco Simón, F. (2001). Sobre la Emergencia de la magia como sistema de alterada en la Roma Augustea y Julio-Claudia. $M H N H, 1,105-132$.

Martínez, A. (2003). La palabra y el silencio en el episodio amoroso de la Eneida. Frankfurt, Peter Lang.

Martínez Astorino, P. (2020). Dido como alusión a Cleopatra en la Eneida. Myrtia, 35, 275-292. 
Mynors, R. (1969). Vergili Maronis Opera. Oxford, Clarendon Press.

Nugent, S. G. (1999). The Women of the Aeneid: Vanishing Bodies, Lingering Voices. En Perkell, C. (ed.), Reading Vergil's Aeneid. An Interpretive Guide (pp.251-270). Norman, University of Oklahoma Press.

Panoussi, V. (2010). Aeneas' Sacral Authority. En Farrell, J. y Putnam, M. C. J. (eds.), A Companion to Vergil's Aeneid and its Tradition (pp. 52-65). Oxford, Clarendon University Press.

Pérez, S. y Barro, A. (2004). Resonare silvas: la tradición bucólica en la poesía del siglo XVI. Santiago de Compostela, Universidad de Santiago de Compostela.

Santos Pinheiro, C. (2010). O percurso de Dido, rainha de Cartago, na literatura latina. Coimbra, Universidade de Coimbra.

Schiesaro, A. (2008). Furthest Voices in Virgil's: Dido. SIFC, 100, 60-162.

Seider, A. (2013). Memory in Vergil's Aeneid. Creating the Past. Cambridge/New York, Cambridge University Press.

Silva, G. (2020). Magic and Memory: Dido's Ritual for Inducing Forgetfulness in Aeneid 4. Mnemosyne, $1-14$.

Stroppini, G. (2003). L'amour dans les livres I - IV de l'Enéide de Virgile, ou Didon et la mauvaise composante de l'âme. Paris, L'Harmattan.

Syed, Y. (2005). Cleopatra and the Politics of Gendered Ethnicity. En Vergil's Aeneid and the Roman Self. Subject and Nation in Literary Discourse (pp. 177-193). Ann Arbor, University of Michigan Press.

Tambiah, S. J. (1990). Magic, Science and Religion and the Scope of Rationality. Cambridge, Cambridge University Press.

Tupet, A. M. (1971). Didon magicienne. Revue des Études Latines, 48, 229-258.

*Guillermina Bogdan es Doctora en Letras por la Universidad de La Plata; Profesora Adjunta del área Latín, Facultad de Humanidades y Ciencias de la Educación. Ha publicado capítulos de libro en volúmenes como C. Beltrao y F. Santangello (eds.) Estátuas na Religiao Romana, Universidad de Coimbra, Portugal, Classica Digitalia, 2020; entre otros; y artículos en revistas internacionales como Praesentia, Auster y Aletheia, entre otras. Ha estudiado la representación de la religio en Virgilio, en especial, en Eneida; actualmente se encuentra trabajando en la sistematización religiosa presente en Varrón, tema sobre el cual ha disertado en el Kolloquium zur antiken Kultur- und Religionsgeschichte, Philosophische, Max Weber Kolleg, Fakultät-Erfurt Universität, en varias oportunidades.

RECIBIDO: 23/04/2021

ACEPTADO: 27/05/2021 